New Directions for Service Research: Refreshing the

Process of Theorizing to Increase Contribution

\begin{tabular}{|r|l|}
\hline Journal: & Journal of Services Marketing \\
\hline Manuscript ID & JSM-01-2019-0048.R2 \\
\hline Manuscript Type: & Article \\
\hline Keywords: & conceptual, marketing processes, User studies, qualitative research \\
\hline
\end{tabular}

SCHOLARONE $^{\text {TM }}$

Manuscripts 


\title{
New Directions for Service Research: Refreshing the Process of Theorizing to Increase Contribution
}

\begin{abstract}
Purpose - For service research to develop as an applied social science there is the need to refresh the process of theorizing so it focuses not only on increasing new academic knowledge but also on knowledge that is managerially relevant. Guidelines are provided to achieve this.

Design/methodology/approach - A theorizing process that integrates general theoretic perspectives and contextual research to develop midrange theory is developed. The process is based on the philosophical foundations of pragmatism and abductive reasoning, which has their origins in the 1950s when the management sciences were being established.

Findings -A recent research stream that develops midrange theory about customer and actor engagement is used to illustrate the theorizing process.

Practical Implications - Practicing managers, customers and other stakeholders in a service system use theory, so there is a need to focus on how theory is used in specific service contexts and how this research leads to academic knowledge that is managerially relevant. Thus, as applied social science, service research needs to explicitly focus on bridging the theory-praxis gap with midrange theory by incorporating a general theoretic perspective and contextual research.

Originality/value - The contribution comes from providing a broader framework to guide the theorizing process that integrates general theoretic perspectives and applied research to develop midrange theory. While general theories operate at the most abstract level of conceptualization midrange theories are context-specific, and applied theory (theories-in-use) embedded in empirical research
\end{abstract}

Key words: theorizing, midrange theory, managerial relevance, abduction, pragmatism critical realism, methodological pluralism

Paper type -Research paper 


\section{Introduction}

Much has been achieved in the last three decades, but major challenges still exist in the services domain of academic research if it is going to mature as an applied social science. Of prime importance is to provide both strong managerial foundations as well as scientific explanations. Rather than just focusing on developing topics leading to substantive knowledge (e.g., Ostrom et al. 2015, Russell-Bennett and Rosenbaum 2019), explicit attention also needs to be given to a process of theorizing that bridges theory and practice.

Over a decade and a half ago, Gummesson (2004 p. 317) drew attention to the failure of academic research to bridge theory and practice. He stated: “... researchers seem to settle for theory on a low level of abstraction or generality and have difficulties seeing the broader, systemic context; the core of a phenomenon is obscured by details and fragments." He went on to say that: "too much research is stuck in the middle neither being firmly based in real-world data nor reaching a sufficient level of abstraction." Benoit et al.'s (2017) recent review of articles published in the Journal of Service Management shows academic research has yet to meet Gummesson's challenge. The review shows service research is fragmented and is largely based on numbers of single, qualitative case studies and quantitative studies, with little attention to the issue of verification of theory or how theory informs practice.

It is important to recognize that the theoretical structures that inform service research are by their nature removed from the empirical world. Thus, the concepts and language used do not resonate with practicing managers. To help bridge this theory praxis gap, the analysis draws on research by Fendt, KaminskaLabbě, and Sachs, (2008). Their extensive review of the failure of remedies to close the theory-praxis gap leads them to conclude that academic research should revisit the work of the 1950s when the management sciences were being established. They note that the founding management scholars, Russell Ackoff, West Churchman and Donald Schön, were trained as philosophers and viewed the development of management science as a pragmatic practice. What is important is not only on producing relevant management knowledge but also on socializing it amongst those involved in its practice. Given the interactive nature of service provision, such socialization seems imperative.

The objective of this paper is to provide new directions for service research to facilitate its maturing as an applied social science based on strong theoretical and managerial foundations. A framework is developed that refreshes the process of theorizing and leads to an increase in both new academic knowledge and managerial relevance. The process explicitly considers how various theoretical interfaces lead to multiple pathways for developing midrange theory. The process recognizes that practicing managers, customers, and other stakeholders in a service system use theory, and so explicit attention 
needs to be given how they use theory. It is recognized that many service researchers gain insight about practices from the business literature, and from consulting work and other interactions, which allows them to be informed about practice. What the theorizing process provides is a scientific procedure to achieve this. The paper extends the recent research by Nenonen et al. (2017), which focused explicitly on the inclusion of managers in theory building. A key consideration is philosophical foundations that the scientific procedures.

The paper has the following structure. Section 2 investigates the processes of theorizing in light of extant literature while Section 3 explores the philosophical foundations that underpin the process for theorizing. Section 4 illustrates the theorizing process works by examining a research stream about customer and actor engagement. The final section draws implications for refining the theorizing process. Because a number of terms used may be new to readers (i.e., instrumentalism, pragmatism, critical realism, abductive learning/reasoning, methodological pluralism, corpus linguistic methods, lexical patterns, corpora), an Appendix that defines these terms is provided.

\section{A Process Perspective}

\subsection{Overview}

In his critical review of the weaknesses of conceptual papers published in management journals, Cornelissen (2017) concludes that a common limitation in the theorizing process is that the theory used is too narrow in scope, and thus the resulting conceptual development lacks strong theoretical foundations. Hence, explicit attention needs to focus on the process of theorizing rather than just focusing on theory as an outcome (Weick 1995). Our approach meets this challenge by paying attention to both 1) theoretical frameworks, and 2) managerial practices to inform research processes.

To develop a better understanding of the theorizing process that interfaces with theory and practice, it is important to consider the nature of theory. As a starting point, it is recognized that "theory is a statement of concepts and their interrelationships that shows how and why a phenomenon occurs" (Corley and Gioia 2011 p. 12). Brodie et al., (2011b) distinguishes between three types of theory.

General theories: These are conceptions and perspectives utilizing theory that is framed at the highest conceptual level and provides a perspective or logic of explanation for a domain. The theories are broad in scope, integrative and context-free, and thus do not directly lead to empirical investigation. They provide the foundations for understanding and explanation. 


\begin{abstract}
Midrange theory: Midrange theory is context specific. Hence it provides frameworks that can be used to undertake empirical observation and models to guide managerial practices. Most of the theories currently used in service research have these characteristics.
\end{abstract}

Applied theory: Applied theory is embedded in empirical research and context. While the focus of applied theory has traditionally been with empirical research, "theories-in-use" can play an important role. Theories-in-use recognizes that practicing managers, customers, and other stakeholders in a service system use theory. Theories-in-use is context-specific and can be based on tacit mental models.

General theories are broader in scope and more integrated midrange theories (Hunt 1983). Their broader scope means that they need to explain a larger number of phenomena, while their integrative nature means that they serve to unify other less general theories and other general theoretic perspectives. They provide the foundations for understanding and explanation. As noted by Benoit et al. (2017), ServiceDominant (SD) Logic is the most commonly used general theoretical approach in service research. However, there are other choices for service researchers such as Structuration Theory (Giddens, 1984), Social Constructivism (Latour and Woolgar 1989) and Evolutionary Theory (Dennett 1995). Additionally, while the formal status of a general theory may not be established, the underlying 'logic' provides an accepted general theoretic perspective (e.g., Actor-Network Theory; Latour 2005).

There is an inherent difficulty with the interface between general theory, empirical research, and managerial practice. For example, Weick (1989) notes that general theories about organizations involve so many assumptions and such a mixture of accuracy and inaccuracy, that virtually all conjectures remain plausible. He argues that self-interest can become a substitute for validation during theory construction. Thus, "middle-range theories are a necessity if the process is to be kept manageable" (p. 516). It is midrange theory that bridges general theory and applied theory. The concept of midrange (middle range) theory was first introduced into sociology by Merton (1967) as a theory that bridges (connects) general theory and empirical investigation. He defines midrange theories as:

"...theories that lie between the minor but necessary working hypotheses that evolve in abundance during day-to-day research and all-inclusive systematic efforts to develop a unified theory that will explain all the uniformities of social behavior, social organization, and social change." (p. 39)

While the management disciplines have given explicit attention to the use of midrange theory (cf. Pinder and Moore 1980), it has only recently received explicit attention in the marketing and service disciplines (cf. Brodie et al. 2011b, Gummesson 2014, Vargo and Lusch 2017, Brodie and Löbler 2018). In addition 
to empirical research, in applied theory, the role of practitioner knowledge is recognized. Cornelissen's (2002) draws on Schön's (1983) notion of 'reflective practitioners' and the work on the interface of theory and practice by Argyris and Schön (1974), and Zaltman, LeMasters and Heffering (1982) to articulate the concept of 'theories-in-use.' This research recognizes that service practices and practitioners' experiences of previous actions lead to expertise that can offer important insight for theory development. However, the process by which practitioners absorb understandings means that theory development may have subtle differences and therefore, indirect and formal processes are required to theorize with managers (Nenonen et al. 2017). However theories-in-use should not only include practitioners but also include reflective customers and other reflective stakeholders. This offers some departure from the traditional theoretical concerns found in much current service research, which tends to focus on either service provider actions or service recipient experiences (Benoit et al. 2017). Theories-inuse focuses on the interactive and self-reflexive nature of service encounters from multiple perspectives and focuses on explanatory power rather than predicting outcomes. The next sub-sections explore how this process perspective on theory development relates to domains of knowledge.

\subsection{Domains of Knowledge and Scientific Explanation}

Fundamental to the theorizing process is the role of a paradigm that provides the lens or perspective used. According to Kuhn (1962), paradigms "provide models from which spring particular coherent traditions of scientific research (p.10)." Paradigms, therefore, are not theories because they do not allow researchers to advance testable propositions and law-like generalizations. Instead, paradigms are the foundations of the theory, or a metatheory, because they give theory building within a field of study direction and meaning.

As discussed by Vargo and Lusch (2017), paradigms provide the "outer ring" for the recursive theorizing process between general theory, midrange theory, and applied research. While a theory explains something, a paradigm does not explain something. Paradigms decide which kinds of explanations are appropriate in the area of investigation. Brodie and Löbler (2018) note that within an area of investigation paradigms are usually not explicitly considered but rather tacitly provide the meta-theoretic basis for understanding and knowledge development. This leads to a sociological notion of a paradigm, where the paradigm provides the implicit consensual beliefs of a self-contained community or school of thought.

Figure 1, shows how a paradigmatic perspective provides the 'outer ring' for the theoretical and empirical domains of knowledge, and where midrange theories bridge general theory and applied theory.

\section{Figure 1 about here}


It is important to differentiate scientific theory from theory per se in the theory development process. In marketing, Hunt (1983 p. 10) defines scientific theory thus: "Theories are systematically related sets of statements, including some law-like generalizations that are empirically testable. The purpose of theory is to increase scientific understanding through a systematized structure capable of both explaining and predicting phenomena". More broadly, in the context of social science, Bouden (1991) defines a scientific theory thus: "[it] is a set of statements that organize a set of hypotheses and relate them to segregated observations. If a 'theory' is valid, it 'explains' and in other words 'consolidates' and federates empirical regularities which on their side would otherwise appear segregated" (p. 520). In these definitions, the scientific theory provides 'explanation.' A scientific theory, therefore, must explain something, rather than state or make claims. The issue of legitimization of scientific theory and explaining the testing and verification of hypotheses is a question for the philosophy of science. Within different beliefs, differing legitimization procedures are appropriate (Löbler, 2011; Peters et al., 2014).

As outlined in Figure 1, midrange theory bridges general theory and applied theory and hence provides a scientific basis to investigate empirical research questions and theories in-use in service research. Thus, midrange theories are intermediate to the comprehensive analytical schema that can lead to hypotheses, which can be investigated empirically and must explain real-world phenomena. Midrange theory needs to meet the requirements of a 'social causal mechanism' to provide scientific explanation and not just a statistical association (Brodie and Löbler 2018). As discussed by Hedström and Yliskoski (2010), social causal mechanisms have received considerable attention in the social sciences as well as in the field of philosophy of science. It is only recently that Mason, Easton, and Lenny (2013) explored social causal mechanisms in the marketing literature. In doing so, they recognized that midrange theory underpins causal mechanisms: “...causal mechanisms offer a bridge between the philosophical and the empirical. Instead of building up an explanation from first principles - entities, powers, and liabilities, etc. researchers can ask themselves by what mechanisms have the particular events that they are seeking to understand been brought to pass" (Mason et al., 2013 p. 354).

\subsection{Interfaces for Theorizing}

As discussed, academic service research to date has had an empirical focus with large numbers of single, qualitative case studies and quantitative studies, with little attention to the issue of verification of the theory and theories-in-use (Benoit et al. 2017, Nenonen et al. 2017). Thus, such service research has had a tacit interface of midrange theory and empirical research. Recently, an alternate approach to theorizing in the service research domain is advanced that adopts a broader approach and explicitly considers how various interfaces lead to multiple theoretical pathways that enhance the theorizing process (Brodie and Löbler 2018). The advantages of this approach are first that it recognizes that as an applied social science 
service research is inherently interdisciplinary. Hence different general theoretic perspectives can interface with other midrange theories. Second, other midrange theories can interface to develop a focal midrange theory. Third, applied theories which include theories-in-use, as well as empirical research, can interface to develop a focal midrange theory. In Figure 2, the two-way pathways for these interfaces are outlined. That recognizes that the interfaces allow for iterative and recursive processes of theory discovery and theory legitimization guided by abductive reasoning.

\section{Figure 2 about here}

Figure 2 identifies a means to distinguish between the focal general theoretic perspective and other general theoretic perspectives. Within service research, SD logic is the most common general perspective used to interface with midrange theory (Benoit et al. 2017). However, it is important to recognize SD logic is a synthesis of other general theories, including institutional theory, systems theory, complexity theory and complexity economics, and evolutionary theory (Vargo and Lusch 2017). Specific examples where authors have interfaced other general theory with SD logic to develop midrange theory include practice theory (Kjellberg and Helgesson 2006, Schau, Muñiz Jr, and Arnould 2009), actor-network theory (Chandler and Vargo 2013) and systems and ecosystems theory (Frow et al., 2014). The recent attention to institutional theory is of importance because it focuses on the coordination and co-operation mechanisms within the shared institutional logics of institutional arrangements, and so brings SD logic closer to empirical investigation and the need for midrange theory (Vargo and Lusch 2016).

While a focal general theoretic perspective can interface directly with midrange theory, other general theoretic perspectives also provide pathways that can lead to other midrange theories, which then leads to a focal midrange theory. For example, when defining the conceptual domain for customer engagement Brodie et al. (2011a) drew extensively on theory from psychology, sociology, political science, and organizational behavior literature as well as SD logic.

Applied theory based on quantitative and qualitative empirical research can also serve as an input for developing and refining a focal midrange theory. Also, applied theory can include theories-in-use, which provides a valuable interface when developing midrange service theory. As discussed, theories-in-use can include all actors. Not only reflective managers but reflective customers and other reflective stakeholders can provide insight to develop midrange theory.

Nenonen et al. (2017), in their detailed literature review on collaborative theorizing processes, specifically focused on research streams that involve managers as active participants in these processes. These include naturalistic inquiry (Lincoln and Guba, 1985), cooperative inquiry (Reason, 1988), collaborative research (Shani et al. 2008; Pasmore et al. 2008), action research (Dickens and Watkins, 1999; Reason 
and Bradbury, 2006), clinical research (Normann, 1977; Schein 1987, 1995), engaged scholarship (Van de Ven and Johnson, 2006), interactive research (Gummesson, 2001), and consortium benchmarking (Schiele and Krummaker, 2011). Of particular relevance is Design Science research in the Information Systems discipline (e.g., Gregor and Hevner 2013) because it adopts a systems approach.

Based on these collaborative theorizing processes, Nenonen et al. (2017) develop a research procedure that accesses managers' theories in use. It involves working with reflective practitioners and empowering them in the theorizing process. Nenonen et al. (2017) identified twelve themes when designing collaborative research processes. The research shows that theorizing with managers and drawing on theories-in-use leads to useful, usable, and insightful midrange theory. While Nenonen et al. (2017) outlined procedures to collaborate with practicing managers, service research procedures could be used to theorize with other market actors, including customers and other stakeholders. This would better reflect the interactive and networked nature of many service situations.

Online resources, social media, and other sources of managerial writings are becoming increasingly important as sources of input for midrange theorizing based on theories-in-use (Brodie 2017). Data mining and corpus linguistic methods provide the ability to access very large corpora and narratives. For example, in service research, Fehrer, Brodie, and Smith (2015) developed a corpus-linguistic approach for the identification of recurring lexical patterns and the comparison of different corpora, based on managing large-scale text data. This methodology facilitates a theorizing process that clarifies the relationships between transcending concepts of SD logic and midrange theory, and that creates bridges between SD logic, empirical research, and managerial practice for service researchers.

\section{Philosophical Foundations}

\subsection{Overview}

The philosophical foundation for the theorizing process used to develop the midrange theory are now comsidered (see Figure 3). Ontologically a realist pragmatic approachis proposed that emphases the link between action and truth based on explanatory social causal mechanisms, informed by critical realist concerns regarding the nature of truth and its correspondence to reality and it's evaluative (not just descriptive) nature. Epistemologically the use of abductive reasoning is adopted as a way of exploring the nature of knowledge about service phenomena. As theory evolves simultaneously and interactively with empirical observation and allows for the introduction of surprise, novelty, creativity, and innovation in the theory-building process. Finally, methodologically, a methodological pluralist approach is proposed. In 


\subsection{Philosophical approach: pragmatism meets critical realism}

By explicitly including theories-in-use in this fresh thinking approach to service research, embraces the principles of pragmatism. However, it is acknowledge that the term 'pragmatism' needs some qualification. As Fendt et al. (2008) suggest, a return to pragmatism is needed to produce and socialize relevant management knowledge. Pragmatism (Dewey, 1929; James, 1907; Peirce, 1905, 1997) is a philosophical tradition that emphasizes the link between action and truth, positing that the definitive test of knowledge is the readiness to act on it. Furthermore, "classical pragmatists rejected the Cartesian view that thought and action, mind and body, are ontologically distinct' and instead viewed humans as problem solvers whose thoughts guide action in the service of solving practical problems that arise in the course of life (Gross, 2009 p.366).

Pragmatism's strengths include the fact that its practical focus makes it useful in building theory that is appropriate to specific conditions and circumstances and conforms to managerial experience. It recognizes that the configuration of actors, problem situations, habits, and patterns of aggregation of which they are composed is what makes a theory based on explanatory social mechanisms unique (Gross, 2009). "Pragmatists would view social mechanisms as composed of chains or aggregations of actors confronting problem situation and mobilizing more or less habitual responses" (Gross, 2009 p. 368 ). It relates to experiential knowledge or knowledge that is evaluated regarding practical success or failure rather than truth (Mingers, 2014).

However, it is recognized there are two major limitations to the pragmatist approach. Firstly, there are issues in establishing truth purely by consensus, a key premise in pragmatism. Because it does not concern itself with what is (or might be) true, only with what appears, by consensus, to work best, it leaves itself open to the development of false theories. As Mingers (2014) notes, if the purpose of social science is essentially a practical activity aimed at producing useful knowledge rather than understanding 
the true nature of the world, then the meaning of a concept will be specified purely regarding the actual practical effects that it has. The theory would be that which comes to be believed by a community of scientists in the long term, rather than as correspondence to reality (Mingers, 2014). Mingers (2014 p. 159) recognizes that, "[...] although while a true theory should be successful, it does not follow that a successful theory is true". This is because a purely pragmatic approach would focus on the "know what" rather than the "know why" of a particular phenomenon (Polanyi, 1958).

To address this limitation, the relationship between pragmatism and realism is explored. The link between pragmatism and realism is not new, and indeed the philosopher Putman proposed an approach to realism, which he termed pragmatic realism. In this, he proposed that causation was not an absolute relation but one that was intimately related to the perspective of the observer. He was particularly anti-realist in accepting that there might be an objective order or identity to things (Putman, 1987). However, Sosa (1993), in his critique of Putman's work, contended that this need not be the case: “... from the fundamentally and ineliminable perspectival character of our thought it does not follow that reality itself is fundamentally perspectival. Everything that is true relative to a perspective and everything that is false relative to a perspective may be as it is as a necessary consequence of the absolute and nonperspectival character of things" (Sosa, 1993 p. 608). Putman's (1987) strength, however, was to insist that realism is not incompatible with conceptual relativity. In general, a realist understanding of science takes the view that certain types of entities, be they objects, forces, social structures, or ideas, exist in the world, largely independent of human beings and that reliable, although not perfect, knowledge can be gained from them (Bhaskar, 2008; Mingers, 2014). A realist approach maintains that there is an independently existing world of objects and structures that are causally active, giving rise to the actual events that do and do not occur, but at the same time, observations of them can never be pure and unmediated.

The second limitation of classical pragmatism relates to its separation of values and facts when assessing what is useful. A purely consensus-based pragmatic approach might support the status quo or favor some practical outcomes (and some members of the scientific or practitioner community) over others.

Introducing a realist approach to pragmatism (see, for example, Hunt, 2005 or Bhaskar, 2008) allows us to assess theory from an evaluative as well as a factual point of view. Hunt's $(1990,2005)$ model of scientific realism recognizes that theory may have implications (i.e., explanations or predictions) that can be compared or tested in the external world. Also, it recognizes that the theory may have direct effects on the world through influencing, changing, and challenging the beliefs and behaviours of people.

Thus, both facts and values are important features of assessing the usefulness of theories. Thus, to address these challenges and to avoid 'vulgar instrumentalism' (Bertilsson 2004), it is proposed that in-service research, the principles of pragmatism should be complemented by the principles of critical realism when 
theorizing about social systems. Therefore, the greater its explanatory power regarding what might (at least partially) be understood as real in a service setting, the more useful a theory is. A call for the use of complementary approaches in service research is not new. Järvensivu and Törnroos (2010) propose a continuum of ontological and epistemological world views. At one extreme, naïve realists use a deductive research process that begins with theoretical argumentation and then tests arguments with empirical observations. At the other extreme, naïve relativists start with subjective accounts of lived experiences on which they inductively build theory. In between these two extremes lies the critical realist view and what they identify as moderate constructivist approaches. More recently, Anderson Medlin and Törnroos (2019) explore the realist and constructivist approaches in a research process through time.

The realist approach (and in particular critical realist approach) enhances pragmatism by re-defining the assessment of truth and usefulness. Ultimately, what works best is what increases our ability to explain phenomena. Therefore, the greater its explanatory power regarding what might (at least partially) understand as real, the more useful a theory is. It implies a shift in focus for service research from determining theoretical insights based on the observation of the researcher alone to one that is more situationally embedded because it is inclusive of managerial insights. When one wishes to enhance the usefulness of theory by building theory relevant to practice, they should start with the phenomena managers are sensitive to and that matters to them. This revised focus in service research on theories-inuse emphasizes managers' empirical experience of the world that enables us to increase its explanatory power because they often have deeper insights about what is "real" in a situation than outsiders can. Building theory, while taking into account practice, allows researchers to engage in the important work of building consensus. Theorists such as Hunt (1990, 2005), Bhaskar (2008), and Mingers (2014) all recognize consensus building as an important means of understanding the world. Scholars are better able to understand the embeddedness and contextual features of any theory-building because managerial inclusion provides a longer-term view.

In summary, moving away from predictive approaches in service research in favor of explanatory power by adopting a realist approach to pragmatism has benefits. Specifically, it produces relevant knowledge in service contexts, and theory that has implications (i.e., explanations or predictions) that can be compared or tested in the external world. It also emphasizes the relationship between action and truth and focuses on experiential knowledge and problem-solving. Thus, the theory has direct effects on the world through influencing, changing, and challenging the beliefs and behaviors of people. It also allows for both descriptive (facts) and evaluative (values) knowledge and thus recognizes that both facts and values are important features when assessing the usefulness of theories. Finally, it does not rely solely on consensus as an arbiter in theory development but stresses that ultimately what works best is what increases the 
ability to explain phenomena and assumes that a true theory always is a better (or more powerful) theory if it provides a better explanation.

\subsection{Mode of inference: abduction}

Fendt et al. (2008) highlight the importance of interfacing management research with practice. Abductive reasoning plays a key facilitating role in these processes by interfacing theoretical knowledge and empirical understanding. While abductive reasoning is usually discussed in the context of qualitative research (Dubois and Gadde 2002), it is also relevant to quantitative research in services and hence facilitates methodological pluralism. It is important to recognize the multifaceted roles and nature of the abductive reasoning process along the sequence from discovery to justification. When it comes to the different modes of inference or reasoning processes, there are several indications that abductive inquiry is especially suitable when theorizing in service research.

First, there are strong links between the philosophical underpinnings of collaborative theorizing, pragmatism, and critical realism, and abduction. The founder of pragmatism, Charles Sanders Peirce $(1905,1997)$, researched abduction extensively and portrayed it as central to pragmatism. In a similar vein, critical realism (Bhaskar, 2008) focuses on the use of abductive reasoning, or what they term retroduction. Second, most accounts of collaborative theorizing depict processes in which conceptual development and empirical observation are intertwined, suggesting de facto abduction. As stated by Dubois and Gadde (2010 p. 131), when an abductive approach is used, "theoretical frameworks evolve simultaneously and interactively with empirical observation."

The review of the philosophy of science and management literature by Nenonen et al. (2017) indicates that the concept of abductive reasoning can be applied in different ways. As Aliseda (2006) points out, the word 'abduction' refers to the end-product of the reasoning process (i.e., 'abductive explanation') or parts of the process. Building on Peirce's $(1905,1997)$ view that abductive reasoning is the primary foundation for discovery, Nenonen et al. (2017) note that the approach of van Maanen et al. (2007) begins with an unmet expectation and then works backward to create a plausible theory, thus using abductive reasoning to render meaning to the discovery. This definition is similar to critical realists' notion of retroduction, which is a " $[\ldots]$ mode of inference in which events are explained by postulating (and identifying) mechanisms which are capable of producing them [...]" (Sawyer, 1992 p. 107). Retroduction means 'moving backward,' and its key question is, "What must be true to make this event possible?"

Dubois and Gadde (2002) talk about abductive matching in the context of case studies. They stress that abductive reasoning is more suitable in theory development than in the generation of completely new theories. They also point out that the role of the framework in abductive reasoning differs from deductive 
and inductive studies: "In studies relying on abduction, the original framework is successively modified, partly as a result of unanticipated empirical findings, but also of theoretical insights gained during the process" (Dubois and Gadde, 2002 p. 559). Because Dubois and Gadde (2002) emphasize the use of abductive reasoning for the discovery of new concepts, variables, and/or relationships, they state that abduction is more suitable for theory development (i.e., the context of discovery) rather than theory confirmation (i.e., the context of justification). This distinction is also recognized by Magnani (2001), who differentiates creative and selective abduction. According to him, creative abduction relates to the discovery of both the reason and its consequences (such as the discovery of a new disease and its symptoms) whereas selective abduction refers to selecting plausible hypotheses to link the observed consequences to its knowable reason (such as selecting the most likely disease based on its symptoms from a medical encyclopedia). Thus (as noted by Nenonen et al., 2017) conceptual development lies at the heart of abduction, and the successive refinement of concepts constitutes both an input and an output of an abductive study.

Abductive reasoning seeks to provide explanations of the phenomenon, rather than attempting to predict (i.e., deduction) or describe (i.e., induction) such phenomenon. Directions for future service research have included the need for multi-disciplinary integration, a greater focus on complex value networks, and the need for an understanding of how to create transformative services that foster societal change (Patricio, Gustafsson, and Fisk, 2018). Abductive reasoning offers a departure from much current service research work and supports these directions. While empiricism normally focuses only on the analysis of empirically available quantitative data and the statistically significant associations within that data set, abduction emphasizes the importance of the mechanisms that underlie them. It does not make empiricism wrong, and abductive reasoning has no problem with the descriptive analysis of empirical data. The problem arises when that data is subjected to probability statistics and hypothesis testing (Mingers, 2014). This analysis relies on both the assumption that the phenomenon observed takes place within a closed system (i.e., all contingencies are controlled for) and that it is the result of the constant conjunction of events. It takes little account of the unobserved phenomenon that may be present, the contingent factors that are in operation, nor the complex and multidimensional nature of the associations within the system (Mingers, 2014).

By forming explanatory hypotheses from observed events (usually unexpected events that do not conform to our current understanding or theories) Mingers (2014) calls for an imaginative leap to think of some plausible explanation which is neither an induction from a particular instance of the event nor a deduction from a general law or rule based on pre-existing theory. He states: "Abduction is the point where novelty, innovation, and creativity enter the scientific method, as indeed they must" (Mingers, 2014 p. 53). 
Drawing on Nenonen et al. (2017), the following definitions for abductive reasoning are identified from the literature: First, a characteristic of abductive reasoning is the interplay between the conceptual and empirical domains. This could be extended to embrace the entire process of creative and critical theorizing that gives primacy to the empirical world, or abductive reasoning can apply to specific parts of the theorizing process (Nenonen et al. 2017). The specific parts of the theorizing process are:

1. The part responsible for the identification of a formerly unknown phenomenon and the related plausible propositions (hypotheses).

2. The part responsible for generating plausible propositions (hypotheses) and explanations for a known phenomenon.

3. The part responsible for identifying the most plausible propositions (hypotheses) and explanation for a known phenomenon.

Nenonen et al. (2017) emphasize the need for increased specificity when describing abductive research processes: They go on to say: "Labeling such theorizing simply as abductive without explicating how and when abduction has been used is the easy way out - and given the existing concerns about the lack of rigor in collaborative theorizing ( $c f .$, Kieser and Leiner, 2009) sloppy descriptions of theorizing processes merely amplify these trepidations" (p. 1134). Thus, an explanation of how and when abduction has been used is necessary if researchers are to address the lack of rigor in collaborative theorizing (cf., Kieser and Leiner, 2009). Lack of such explanations leads to sloppy descriptions of theorizing processes and amplifies these concerns.

In summary, this discussion suggests that there are different interpretations of abductive reasoning. However, they all rely primarily upon the interplay of the conceptual and the empirical domains and seek to capture the entire process of creative and critical theorizing that gives primacy to the empirical world. It includes the identification of a formerly unknown phenomenon, the generation of plausible hypotheses and explanations for a known phenomenon and identifying the most plausible hypothesis or explanation for such a phenomenon.

\subsection{Methods: methodological pluralism}

Theorizing in service research is not limited to any particular method - and nor does it favor qualitative methods above the quantitative. On the contrary, it is suggested that theorizing in service research requires the use of multiple methodological tools within a single research study. 
Foxall (1993) makes the case for adopting methodological pluralism argueiing for a multi-paradigm approach in consumer research. Tadajewski (2008) also emphasizes the importance of a philosophical and methodological approach based on methodological pluralism. In industrial marketing, Matthyssens and Vandenbempt (2003) and Järvensivu and Törnroos (2010) argue the need for methodological pluralism to get the right balance in theory building and theory testing.

Dubois and Gibbert (2010) suggest that there are at least two reasons for methodological plurality. First, different methodological camps disagree on how to categorize different approaches at any given point in time, let alone over time. They cite the example of shifts in interpretations of research design in grounded theory, case research, and positivist methodological thinking. A second reason for plurality is that studies using different approaches may inspire each other theoretically, empirically, and even methodologically. The choices and iterations and how method, theory, and empirical evidence are used, evolves during the research process and is inherently context-specific. "Hence, essential questions like How to case a case? And, how to theorize from case studies? cannot be addressed in general but need to be contemplated for every case study" (Dubois and Gibbert, 2010 p.135).

Mingers (2014) puts forward three main reasons for the use of multiple methods in research design. His first reson is that the real world is complex and multidimensional and unlikely to be adequately served by particular research methods that focus only on specific aspects. Mingers and Brocklesby (1997) proposed three worlds of investigation in research: (1) the material world of actual and possible states of affairs, (2) the social world of normative social relations and interactions, and (3) the personal world of experiences and beliefs. No one method can hope to capture the richness of each world on its own, let alone their inter-relationships. Mingers' (2014) second reson is that research is not an event but a process of discovery, with discrete phases and different activities, each of which can be predominant at any particular time, multiple methods are a necessity in most research designs. His third reason is that multiple methods in a research design allows for and encourages triangulation and helps to generate more interesting and stimulating results.

In addition to these more generic rationales for methodological pluralism, the use of abduction and recognizing the value of theories-in-use puts forward a case for embracing multiple methods. For example, van Maanen et al. (2007) outline the methodological implications of abduction. First, they propose that researchers should ensure sufficient richness and detail in their data to enable an explanation of why the causal propositions they put forward are plausible. Second, they suggest researchers need to be ready for a lengthy process to move back and forth between conceptual and empirical domains. This substantiates conceptual explanations by developing theoretical consequences and checking these expanded conceptual developments against empirical data. Third, researchers need to adhere to the so- 
called principle of opposites (see also Bailyn 1977), which calls for quantitative analysis with qualitative data and appreciating the qualitative nature of quantitative data (by, e.g., examining the extremes or outliers instead of merely eliminating them).

Finally, service research based on abductive reasoning needs methodological pluralism to illuminate tacit understanding. In abduction, the focus is on both the observed and that which is expected but not observed. Therefore, the search is for the underlying generative mechanisms that account for both that which is present, but also that which may be absent and why. Abductive reasoning is particularly useful for this endeavour because it does not limit itself to one particular form of observation or measurement, and this is one of the most persuasive arguments in favour of its use.

In summary, multi-methodological studies in service research are useful because studies using different approaches may inspire each other theoretically, empirically, and methodologically and help the development of midrange theory. The real world is complex and multidimensional and unlikely to be adequately served by any one particular research method, and therefore, no one method can be said to predominate or be preferable in theorizing in service research. Research is a process of discovery with discrete phases and different activities that are predominant at any one time. Finally, multiple methods allow triangulation and help to generate more interesting and stimulating results, and the richness and detail found in the data generated by multiple methods are needed to make explanations plausible.

\section{Exploring the Theorizing Process}

To explore the approach, the theorizing process used in the recent article "Actor Engagement in Networks: Defining the Conceptual Domain" (Brodie et al. (2019) is examined. The article provides a broader network perspective to generalize the conceptual domain of customer engagement (CE) to the domain of actor engagement (AE). Building on the earlier CE conceptualization (Brodie et al. 2011a) a set of propositions that define the conceptual domain for AE are identified.

The following sequence of theoretical interfaces develops the midrange theory to define the conceptual domain for AE.

1. Theories-in-use to inform midrange theory. An extensive examination of changes in business practice was undertaken. It identified the need to develop midrange theory that took a broader network perspective beyond the engagement subject of customers to other stakeholders or actors in networks and service systems; for example, employees, suppliers, distributors, government, the media, and the general public. Of prime importance was the reciprocal, social, and collective nature of engagement beyond dyadic 
interactions. For example, platform businesses such as eBay, Etsy, IBM, and Amazon leverage their connections and open their ecosystems for customers, external software developers, start-ups, universities, or even competitors to engage and thereby cocreate value within the service ecosystem. An initial conceptualization of the multi-actor network perspective of AE was established.

2. Empirical and conceptual research to inform midrange theory. A comprehensive literature review of what had become a substantial research stream about $\mathrm{CE}$ and an emerging research stream about AE was undertaken. What emerged was a conceptualization of CE as one type of AE that focuses on the dyadic relationship between customers and firms. The review provided a foundation for a broader perspective of $\mathrm{AE}$, one that embraces networks involving multiple actor interactions. This systemic perspective of AE reflected the interplay between various levels of aggregation (micro, meso, and macro) within a service ecosystem.

3. Other general theoretic perspectives and other midrange theories to inform the focal midrange theory. Another aspect of the literature review was to pay attention to the general theoretic perspectives and midrange theory that informed the conceptualization of AE. This led to five concepts that underpin the nature of $\mathrm{AE}$ and guide its conceptualization. They are 1) role of actors and agency, 2) system emergence, 3) actor interactions and independencies, 5) institutions as context and 5) institutional arrangements that are enabled and constrained by social processes.

4. Focal general theoretic perspective to inform focal midrange theory. The five concepts that underpin the nature of AE were elaborated on within SD logic to develop guidelines to arrive at the five propositions that defined the conceptual domain of AE.

\section{Theories-in-use to inform focal midrange theory. This part of the theorizing process draws upon the} practices of four companies, each of which uses a different business model.

Throughout this theorizing process, abductive reasoning has facilitated the interplay between the conceptual and empirical domains. It led to the identification of formerly ill-defined phenomenon and developed propositions that generate plausible and comprehensive explanations for actor engagement in networks. Reflecting earlier work on CE (Brodie et al. 2011a), the new fundamental propositions that defined the conceptual domain of AE led to a broad range of managerial implications. First, they allowed managers to strategically define their position within their network and develop strategies to influence and enable the engagement of customers and other relevant actor groups collaborating in their network. Second, they provided a perspective for managers to revise their business models to engage with stakeholders on their preferred or most effective engagement platform. Third, they shed light on what drives the engagement of the different types of actors. Finally, they guided the organizational structures 
and processes to facilitate and support engagement. Also, the broader network perspective of AE was used to develop a comprehensive agenda to establish this new research domain.

The theorizing process to define the conceptual domain of AE builds upon the three research articles that helped to establish a stream of service research about CE (Brodie et al. 2011a, Brodie et al. 2013, Hollebeek et al. 2014). Of note is that each article uses abductive reasoning to guide different sequences of pathways to develop midrange theory (MRT) about CE and AE (see Figure 4).

\section{Figure 4 about here}

The first study, "Customer engagement: Conceptual domain, fundamental propositions, and implications for research" (Brodie et al. 2011a), used a similar sequence of pathways to the Brodie et al. (2019) study. The second study, "Consumer engagement in a virtual brand community: An exploratory analysis," (Brodie et al. 2013) extended the conceptual work on CE and started with empirical research to develop a conceptualization of online brand engagement. In the second step adopted SD logic to provide a broader conceptualization of relationships. It guided and refined the conceptualization of 'online brand engagement.' The third step drew upon theories-in-use and employed a netnographic methodology to interact with members of the online community and led to a refinement of the conceptualization. The third study, "Consumer brand engagement in social media: Conceptualization, scale development, and validation" (Hollebeek et al. 2014) operationalized the previous conceptual work. It started with exploratory qualitative research interacting with reflective customers to develop a scale to measure consumer brand engagement (CBE). In the next three steps, a survey instrument investigates the proposed CBE scale. First, exploratory factor analysis examines the factorial structure and the dimensionality of CBE. Next, employing a new sample, a series of confirmatory factor analyses develop the CBE scale. Finally, an additional sample of consumers explores CBE within a broader nomological net of conceptual relationships.

\section{Implications}

\subsection{Overview}

For service research to develop as an applied social science that provides stronger managerial foundations, there is a need to refresh the process that explicitly considers how various interfaces lead to multiple theoretical pathways that may enhance the process of theorizing. First, general theoretic perspectives can interface with other midrange theories. Second, other midrange theories can interface to develop a focal midrange theory. Third, applied theories, which include theories-in-use and empirical 
research, can interface to develop a focal midrange theory. Of note, while our approach has similarities to Hunt's (2013) inductive realist process approach to theory generation, it differs because it explicitly distinguishes between types of theory (general, midrange, and applied).

Section 4 illustrates the application of the theorizing process by examining the recent paper by Brodie et al. (2019)that defines the conceptual domain of AE. The research about CE highlights the different ways the theorizing process can be applied. Of note, abductive reasoning guides each study but uses a different sequence of pathways for theorizing. 'Theory-in-use' grounds the research in practice. As an applied social science, service research is inherently interdisciplinary, so a synthesis of general theoretic perspectives is required. For the research, SD Logic provides a useful synthesis to provide theoretic foundations.

The theorizing process developed had its origins in the 1950s in the management disciplines. It was seen as important to not only produce relevant management knowledge but also to socialize it amongst those involved in its practice. Ontological foundations based on pragmatic realism and the epistemology on abductive reasoning is adopted. It implies that interfacing with practice is a key aspect of theory development and a feature that is not necessarily apparent in current service research. Also differentiating between levels of theory development (general, midrange, and applied) highlights the differing roles for theory in service research to develop a scientific explanation. While general theories operate at the most abstract level of conceptualization, midrange theories are context-specific, and applied theory (theoriesin-use) are embedded in empirical research. Practicing managers, customers, and other stakeholders in a marketing system use theory, hence there is the need to focus on how theory is used in specific service contexts.

\subsection{Further Research}

This paper builds on the recent work by Nenonen et al. (2017) and Brodie et al.(2017) that explore theorizing with managers to bridge the theory-praxis gap. As recognized by Nenonen et al. (2017) in their detailed literature review on collaborative theorizing processes, specifically focusing on research streams that involve managers as active participants in these processes, similar approaches have been adopted in the management disciplines and serve as a basis for our approach. Of particular relevance in the refinement of our approach is Design Science in the Information Systems discipline (e.g., Gregor and Hevner 2013) because it adopts a systems perspective. Also important is research by Jaworski (2011) and Åge (2014) concerning the way practicing managers use theory. 
Some general questions for further investigation regarding our theorizing process where managers are included as active participants in these processes are:

1. What criteria are appropriate in a given managerial context to guide $t$ quest for explanatory power in service settings?

2. What social causal mechanisms help explain the link between the general and the empirical theory and theory-in-use in any given service situation?

3. What aspects of 'theories-in-use' are most salient to a specific service situation?

4. What helps and hinders the application of theory in a specific service context?

There is also a call for the application of abductive reasoning in service research, which simultaneously and interactively links theoretical frameworks with empirical observation. Abductive reasoning supports explanatory (as opposed to predictive) power by focusing on the underlying mechanisms that may account for what is observed. Some potential research questions are:

1. What constitutes a superior scientific and practical service explanation?

2. When should the focus be on creative abduction (the discovery of both the reason and its consequences) and when on selective abduction (selecting plausible hypotheses to link the observed consequences to its knowable reason) in service research?

3. When should research aimed replicability follow abductive research, and what are the merits of self-replication (Bamberger 2019)?

Finally, it is suggested there is a need for methodological pluralism. Such pluralism can help maintain an openness to new and different ways of conceptualizing and categorizing phenomena. Also, this approach to research reflects more fully the complex nature of the real world and offers the opportunity to triangulate observations and theories to help understand what might constitute a more robust explanation from our data. Some potential research questions are:

1. How to integrate disparate and potentially contradictory findings in multimethodological service studies?

2. How to create robust theoretical understanding in service research from multimethodological data such that the strengths and limitations of the different methods are taken into account?

3. What new or novel combinations of methods in service research are needed to reflect the complexity of real-world situations? 


\subsection{Conclusion}

This paper has endeavored to guide how to refresh the process of theorizing in service research is broadens the scope leading to stronger theoretical foundations and greater relevance. Thus, the paper meets Gummesson's (2004 p. 317) challenge of avoiding being "stuck in the middle neither being firmly based in real-world data nor reaching a sufficient level of abstraction." 


\section{References}

Andersen, P. H. Medlin C. T., Törnroos J. (2019). "Re-appraising interaction and process for industrial network research: The future plunging mirror hall metaphor," Industrial Marketing Management Online 13 July 2019

Argyris, C., and Schon, D. A. (1974). Theory in practice: Increasing professional effectiveness. San Francisco: Jossey-Bass.

Aliseda, A. (2006). Abductive reasoning: Logical investigations into discovery and explanation (Vol. 330). Springer.

Bailyn, L. (1977). "Research as a cognitive process: Implications for data analysis.” Quality and Quantity, 11(2), 97-117.

Baker P. (2006). Using Corpora in Discourse Analysis. Bloomsbury Academic

Bamberger P. A., (2019). "On the Replicability of Abductive Research in Management and Organizations: Internal Replication and Its Alternatives.” Academy of Management Discoveries, 5 (2), $103-108$.

Bertilsson, T.M., (2004). "The elementary forms of pragmatism: on different types of abduction," European Journal of Social Theory, 7(3): 371-389.

Benoit, S., Scherschel, K., Ates, Z., Nasr, L. and Kandampully, J., (2017). "Showcasing the diversity of service research," Journal of Service Management, 28 (5), 810-836.

Bhaskar, R., (2008) [1975]. A Realist Theory of Science (3rd edition). Verso: London

Bowden, Jana L.-H. (2009). “The Process of Customer Engagement: A Conceptual Framework,” The Journal of Marketing Theory and Practice, 17 (1), 63-74.

Brodie, R. J. (2017). Enhancing theory development in the domain of relationship marketing: How to avoid the danger of getting stuck in the middle. Journal of Services Marketing, 31(1), 20-23.

Brodie, R. J., and Loebler H. (2018). Advancing Knowledge about Service-Dominant Logic: The Role of Midrange Theory Chapter 33 Sage Handbook on Service-Dominant Logic

Brodie, R. J., Hollebeek, L. D. Juric, B., and Ilic, A. (2011a). "Customer Engagement: Conceptual Domain, Fundamental Propositions, and Implications for Research,” Journal of Service Research, 14(3), 252-271.

Brodie, R. J., Saren, M., and Pels, J. (2011b). "Theorizing about the Service Dominant Logic: The Bridging Role of Midrange Theory," Marketing Theory, 11(1), 75-91.

Brodie, R. J., Fehrer, J. A. Jaakkola, E., and Conduit, J. (2019). “Actor Engagement in Networks: Defining the Conceptual Domain," Journal of Service Research, 22 (2) 173188.

25

Brodie, R. J., and Juric, B. (2018). "Customer engagement: Developing innovative research that has scholarly impact," Journal of Global Scholars of Marketing Science, 28 (3), 291-303 
Brodie, R. J., Nenonen, S., Peters, L. D., and Storbacka, K. (2017). “Theorizing with managers to bridge the theory-praxis gap: Foundations for a research tradition," European Journal of Marketing, 51 (7-8), $1173-1177$

Chandler, J. D., and Vargo, S. L. (2011) "Contextualization and value-in-context. How context frames exchange," Marketing Theory, 11 1, 35-49. Coffey and Atkinson, 1996

Cornelissen, J. P., (2002). “Academic and practitioner theories of marketing," Marketing Theory, 2(1), 133-143.

Cornelissen J. D. (2017) “Editor's Comments: Developing Propositions, A Process Model or a Typology? Addressing the Challenges of Writing Theory without a Boiler Plate," Academy of Management Review $4211-9$

Corley, K. G., and Gioia D. A. (2011) "Building Theory About Theory Building: What Constitutes a Theoretical Contribution?” Academy of Management Review, 36(1), 1232

Dennett, D.C., 1995. Darwin's dangerous idea. The Sciences, 35(3): 34-40.

Dewey, J. (1929). The quest for certainty. Minton Balch And Company

Dickens, L., and Watkins K. (1999). “Action research: rethinking Lewin.” Management Learning, 30(2), 127-140

Dubois, A., and Gadde, L. E. (2002). "Systematic combining: an abductive approach to case research." Journal of Business Research, 55(7), 553-560.

Dubois, A., and Gibbert, M. (2010). "From complexity to transparency: managing the interplay between theory, method, and empirical phenomena in IMM case studies." Industrial Marketing Management, 39, $129-136$.

Fendt, J., Kaminska-Labbě, R., and Sachs, W. (2008). "Producing and socializing relevant management knowledge: Re-turn to pragmatism,” European Business Review, 20(6), 471-491.

Fehrer J., Brodie R J. and Smith S., (2015) "Theorizing in Marketing using Corpus Linguistics: A New Methodological Framework EMAC Conference Leuven Belgium," June 7 pages

Foxall, G. R. (1993). "Consumer behaviour as an evolutionary process.” European Journal of Marketing, $27(8), 46-57$.

Frow P., McColl-Kennedy J. R., Hilton T., Davidson A. Payne A. Brozovic D. (2014). "Value propositions: A service ecosystems perspective.” Marketing Theory, 14 3, 327-351.

26

Giddens, A. (1984). The Constitution of Society: Outline of the Theory of Structuration. Chicago: Polity Press.

Gregor, S., and Hevner A. R., (2013). "Positioning and Presenting Design Science Research for Maximum Impact,’ MIS Quarterly, 37 (2), 337-356.

Gross, N. (2009). "A pragmatist theory of social mechanisms. American Sociological Review, 74 (3): 358-378. 
Gummesson, E. (2001). Are current research approaches in marketing leading us astray?" Marketing Theory, 1(1), 27-48.

Gummesson, E. (2004) "Qualitative Research in Marketing: Road-map for a Wilderness of Complexity and Unpredictability," European Journal of Marketing, 39 (3) 309-327.

Gummesson E. (2014)"The theory/practice gap in B2B marketing: reflections and search for solutions", Journal of Business and Industrial Marketing, 29 (7/8),619-625.

Harman, G. (2016), Immaterialism. Cambridge, UK: Polity Press.

Hedström, P., and Ylikoski P. (2010) "Causal Mechanisms in the Social Sciences," Annual Review of Sociology, 36 (1), 49-67.

Hodgkinson, G. P., and Rousseau, D. M. (2009). Bridging the rigour-relevance gap in management research: it's already happening! Journal of Management Studies, 46(3), 534-546.

Hollebeek, L. D., Glynn, M. S., and Brodie, R. J. (2014). Consumer brand engagement in social media: Conceptualization, scale development, and validation. Journal of Interactive Marketing, 28 (2), 149-165.

Hunt S.D. (1983). "General Theories and the Fundamental Explananda of Marketing.” Journal of Marketing, 47(Fall), 9-17.

Hunt, S. D. (1990). Truth in marketing theory and research. Journal of Marketing, 54(July), 115.

Hunt, S. D. (2005). "For truth and realism in management research," Journal of Management Inquiry, 14 (2), 127-138.

Hunt, S. D. (2013). "The inductive realist model of theory generation: explaining the development of a theory of marketing ethics." AMS Review, 3(2), 61-73.

James, W. (1907), Pragmatism, A New Name for Some Old Ways of Thinking. Popular Jaworski, B. J. (2011). “On Managerial Relevance.” Journal of Marketing, 75 (4) 211-224.

Jaworski, B.J. (2011), “On managerial relevance,” Journal of Marketing, 75 ( 4), 211-224.

Järvensivu, T. and Törnroos, J. (2010). "Case study research with moderate constructionism:

Conceptualization and practical illustration.” Industrial Marketing Management, 39(1), 100-108.

Kieser, A., and Leiner, L. (2009). "Why the rigour-relevance gap in management research is unbridgeable.” Journal of Management Studies, 46(3), 516-533.

Kjellberg, H., and Helgesson, C-F., (2006) "Multiple versions of markets: Multiplicity and performativity in market practice." Industrial Marketing Management 35 (7):839-855.

Kristof, N. (2014), Professors, We Need You! New York Times, February 14, 2014

Kuhn, T.S. (1962), The Structure of Scientific Revolution, Chicago.

Latour, B. (2005), Reassembling the social; an introduction to Actor-Network-Theory. Oxford: Oxford University Press.

Latour, B. and Woolgar, S., (1989), Laboratory Life: The Construction of Scientific Fact. Princeton University Press, Princeton, NJ. 
Lincoln, Y.S., and Guba, E.G. (1985). Naturalistic Inquiry. Sage, Beverly Hills, CA.

Löbler, H. (2011) "Position and Potential of Service-dominant Logic: Evaluated in an 'ism"' Frame for Further Development," Marketing Theory, 11 1, 51-73.

Magnani, L. (2005). An abductive theory of scientific reasoning. Semiotica, 1(4) 261-286

Mason, K., Easton G., and Lenny, P. (2013) "Causal Social Mechanisms; from the what to the why" Industrial Marketing Management 42 347-355

Matthyssens, P. and Vandenbempt, K. (2003). Cognition-in-context: reorienting research in business market strategy. Journal of Business and Industrial Marketing, 18(6/7), 595-606.

Merton, R. K., (1967) On Theoretical Sociology: Five Essays, Old and New, New York, Free Press. Mingers, J. (2014). System Thinking, Critical Realism, and Philosophy: A confluence of ideas. Routledge: Oxon.

Mingers, J., and Brocklesby, J. (1997). "Multimethodology: Towards a framework for mixing methodologies." Omega 25(5) 489-509.

Nenonen, S., Brodie, R. J, Storbacka, K., and Peters, L. D. (2017). “Theorizing with managers: increasing academic knowledge as well as practical relevance.” European Journal of Marketing, 51 (7/8) 1130-1152.

Normann, R. (1977). Management for Growth. New York: John Wiley and Sons. Ostrom, A. L., A.

Parasuraman, D. E. Bowen, L. Patricio, and C. A. Voss (2015), "Service Research Priorities in a Rapidly Changing Context," Journal of Service Research, 18 (2), 127-59.

Pasmore, W. A., Stymne, B. E. N. G. T., Shani, A. B., Mohrman, S. A., and Adler, N. (2008). The promise of collaborative management research. Handbook of collaborative management research, 7-31.

Peirce, C. S. (1905). What pragmatism is? The Monist, 161-181. Peirce, C. S. (1997). Pragmatism as a principle and method of right thinking: The 1903 Harvard lectures on pragmatism. SUNY Press.

Peters, L. D., Lobler, H., Brodie, R.J., Breidbach, C.F., Hollebeek, L.D., Smith, S.D., Sorhammar, D., and Varey, R.J. (2014), “Theorizing about resource integration through service-dominant logic.”Marketing Theory, 14 (3), 249-268.

Pinder, C. C., and Moore L. F., (1980), Middle Range Theory and the Study of Organizations, Martinnus Nijhoff Publishing: Boston

Polanyi, M. (1958), Personal Knowledge (London: Routledge and Kegan Paul) Putnam, H. (1987) The Many Faces of Realism, Lasalle, IL: Open Court

Russell-Bennett, R, Rosenbaum, M S. (2019) "Editorial," Journal of Services Marketing, 33 (1), 1-4, https://doi.org/10.1108/JSM-02

Sawyer, K. (1992). "Improvisational creativity: An analysis of jazz performance," Creativity Research Journal, 5 (3): 253-263.

Schau, H. J., Muñiz Jr, A. M., and Arnould. E. J. (2009) "How brand community practices create value." Journal of Marketing 73 (5):30-51. 
Schein, E.H. (1987). The Clinical Perspective in Fieldwork. Newbury Park, CA: Sage. Schein, E.H. (1995). "Process consultation, action research and clinical inquiry: are they the same?" Journal of Managerial Psychology, 10(6), 14 - 19.

Schiele, H., and Krummaker, S. (2011). "Consortium benchmarking: Collaborative academicpractitioner case study research.” Journal of Business Research, 64(10), 1137-1145.

Schön, D. A. (1983). The reflective practitioner: How professionals think in action (Vol. 5126). Basic books.

Shani, A.B., Mohrman, S.A., Pasmore, W.A., Stymne, B. and Adler, N. (Eds.) (2008). Handbook of Collaborative Management Research, Sage.

Sosa, E. (1993). "Putman's Pragmatic Realism,” Journal of Philosophy, XC (12): 605-626. Starkey, K. and Madan, P. (2001). "Bridging the relevance gap: aligning stakeholders in the future of management research.” British Journal of Management, 12: 3-26.

Tadajewsk, M. (2008). "Incommensurable paradigms, cognitive bias and the politics of marketing theory." Marketing Theory, 8(3) 273-297.

Vargo, S. L., and Lusch, R. F. (2017) "Service-dominant logic 2025” International Journal of Research in Marketing, 34 (1) 46-67.

Van de Ven, A. H., and Johnson, P. E. (2006). "Knowledge for theory and practice." Academy of Management Review, 31(4), 802-821.

Van Maanen J., Sørensen J. B., and Mitchell T.R. (2007) “The Interplay Between Theory and Method," Academy of Management Review, 324 1145-1154. Weick, K. E. (1989) “Theory Construction as Disciplined Imagination,” Academy of Management Review, 14(4), 516-531.

Weick, K. E. (1995), "What Theory is Not Theorizing Is," Administrative Science Quarterly, 40, 385390.

Zaltman, G., LeMasters, K., and Heffering, M. (1982). Theory construction in marketing: Some thoughts on thinking. New York: John Wiley and Sons

Åge, L.-J. (2014), "How and why managers use conceptual devices in B2B research," Journal of Business and Industrial Marketing, Vol. 29 Nos 7/8. 
Appendix: Definition of Terms

\begin{tabular}{|c|c|c|}
\hline Term & Definition & Source \\
\hline $\begin{array}{l}\text { Abductive } \\
\text { learning/reasoning }\end{array}$ & $\begin{array}{l}\text { Events are explained by postulating and/or identifying the } \\
\text { mechanisms capable of producing them. }\end{array}$ & Sawyer (1992) \\
\hline Abductive inquiry & $\begin{array}{l}\text { A foundation for inquiry, beginning with an unmet } \\
\text { expectation and working backwards to create a plausible } \\
\text { theory to render meaning to the surprise. }\end{array}$ & $\begin{array}{l}\text { van Maanen et al. } \\
\text { (2007) }\end{array}$ \\
\hline Applied Theory & Empirically based research and theories -in-use. & $\begin{array}{l}\text { Brodie and Loebler } \\
(2018)\end{array}$ \\
\hline Corpora & $\begin{array}{l}\text { Large bodies of naturally occurring language data stored } \\
\text { on computers }\end{array}$ & Baker (2006) \\
\hline $\begin{array}{l}\text { Corpus linguistic } \\
\text { methods }\end{array}$ & Methods for analysizing copora & Baker (2006) \\
\hline Critical Realism & $\begin{array}{l}\text { A philosophy of science that explores the interface } \\
\text { between the natural and the social sciences and focuses on } \\
\text { the underlying generative mechanisms that may account } \\
\text { for events. }\end{array}$ & Bhaskar (2008) \\
\hline $\begin{array}{l}\text { General (or scientific) } \\
\text { Theory }\end{array}$ & $\begin{array}{l}\text { Theories that provide explanation rather than state or make } \\
\text { claims and form the basis for the legitimization of the } \\
\text { testing and verification of hypotheses. }\end{array}$ & $\begin{array}{l}\text { Hunt (1983) } \\
\text { Bouden (1991) }\end{array}$ \\
\hline Instrumentalism & $\begin{array}{l}\text { Views ideas as useful instruments for solving practical } \\
\text { problems rather than as insights into truth. A form of anti- } \\
\text { realism. }\end{array}$ & Dewey (1929) \\
\hline Lexical patterns & $\begin{array}{l}\text { Words or chunks of text that occur in language with high } \\
\text { frequency; the meaning of the parts are sometimes } \\
\text { different than the meaning of the whole. }\end{array}$ & Baker (2006) \\
\hline $\begin{array}{l}\text { Methodological } \\
\text { pluralism }\end{array}$ & $\begin{array}{l}\text { The acceptance of the use of multiple methodological tools } \\
\text { within a single research study. }\end{array}$ & $\begin{array}{l}\text { Nenonen et al. } \\
(2016)\end{array}$ \\
\hline Mid-range Theory & $\begin{array}{l}\text { Bridges general theory and applied theory providing a } \\
\text { scientific basis to investigate empirical research questions } \\
\text { and theories-in-use. }\end{array}$ & $\begin{array}{l}\text { Brodie and Loebler } \\
(2018)\end{array}$ \\
\hline Paradigm & $\begin{array}{l}\text { Provides a coherent lens or perspective used in theory } \\
\text { development and is used to decide which kinds of } \\
\text { explanations are appropriate in the area of investigation. }\end{array}$ & Kuhn (1962) \\
\hline Pragmatism & $\begin{array}{l}\text { A philosophical tradition that gives emphasis to the link } \\
\text { between action and truth, positing that the definitive test of } \\
\text { knowledge is the readiness to act on it. }\end{array}$ & Dewey (1929) \\
\hline $\begin{array}{l}\text { Realist pragmatic } \\
\text { approach }\end{array}$ & $\begin{array}{l}\text { A pragmatic approach which emphases the link between } \\
\text { action and truth based on explanatory social mechanisms, } \\
\text { informed by critical realist concerns regarding the nature } \\
\text { of truth and its correspondence to reality and its evaluative } \\
\text { (not just descriptive) nature. }\end{array}$ & $\begin{array}{l}\text { Nenonen et at. } \\
(2016)\end{array}$ \\
\hline $\begin{array}{l}\text { Social Causal } \\
\text { Mechanisms }\end{array}$ & $\begin{array}{l}\text { Social causal mechanisms offer an explanation of events } \\
\text { which considers the particular characteristics of causal } \\
\text { relations between social structures, processes, and } \\
\text { activities. Researchers ask themselves by what } \\
\text { mechanisms have the particular events that they are } \\
\text { seeking to understand been brought to pass. }\end{array}$ & Mason et al. (2013) \\
\hline Theories-in-use & $\begin{array}{l}\text { An approach to applied theory which recognizes that } \\
\text { practitioners and practical knowledge can play an } \\
\text { important role in the theorizing processes. }\end{array}$ & Cornelissen (2002) \\
\hline
\end{tabular}


Figure 1 Domains of Knowledge for Theorizing (adapted from Brodie 2017)

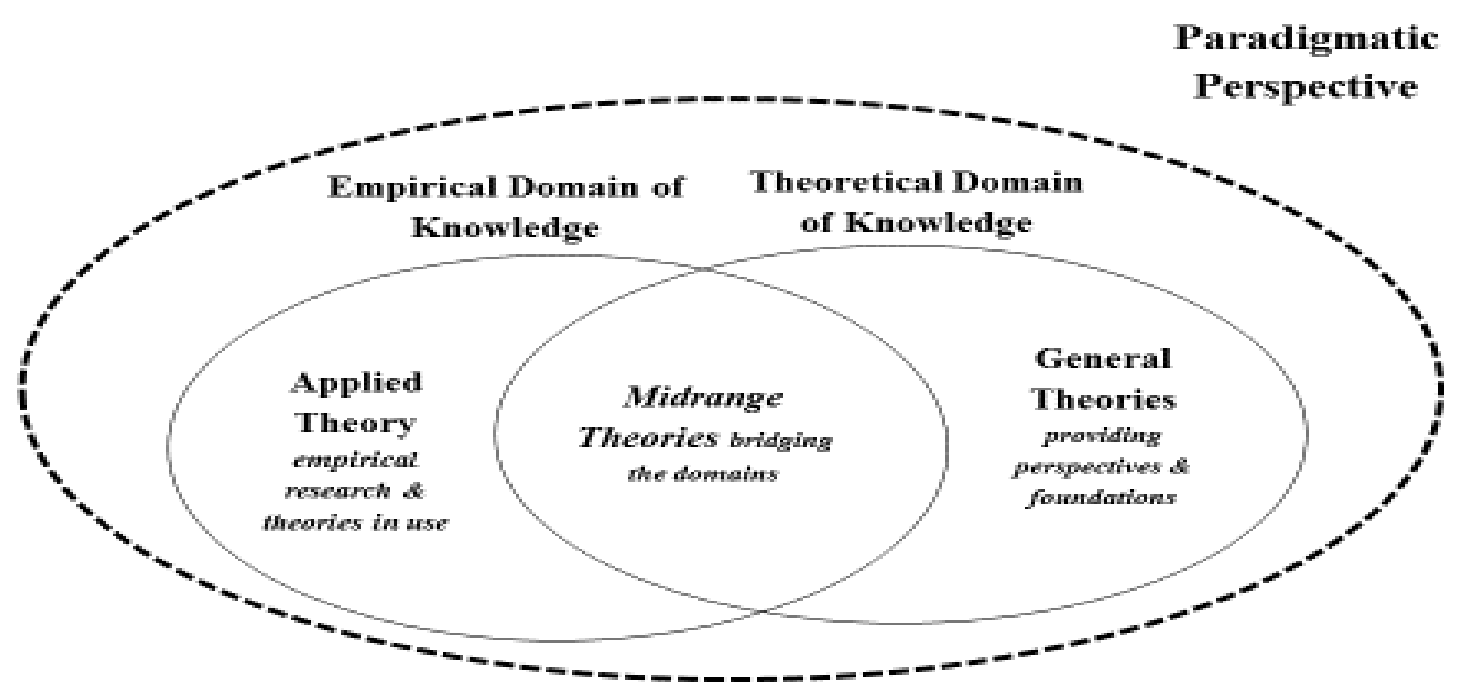


Figure 2 Interfaces for Theorizing (adapted from Brodie and Löbler 2018)

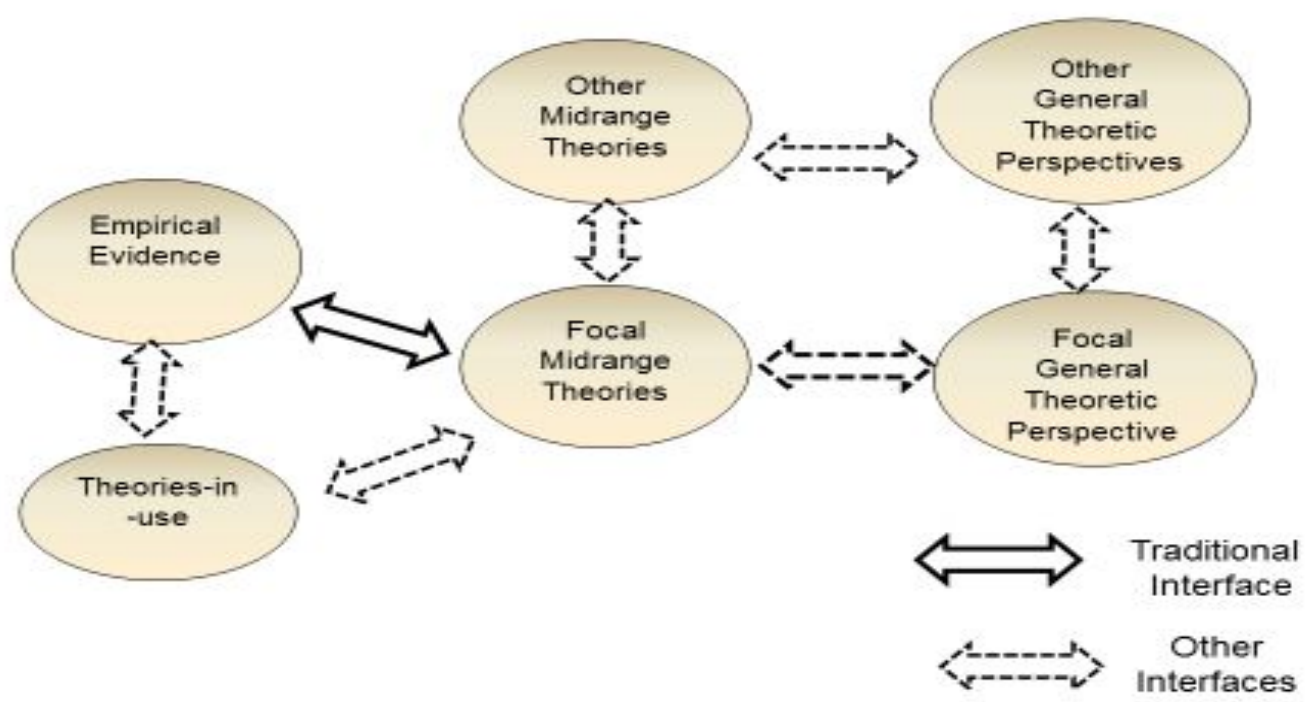


Figure 3: Philosophical Foundations for Theorizing about Midrange Theory

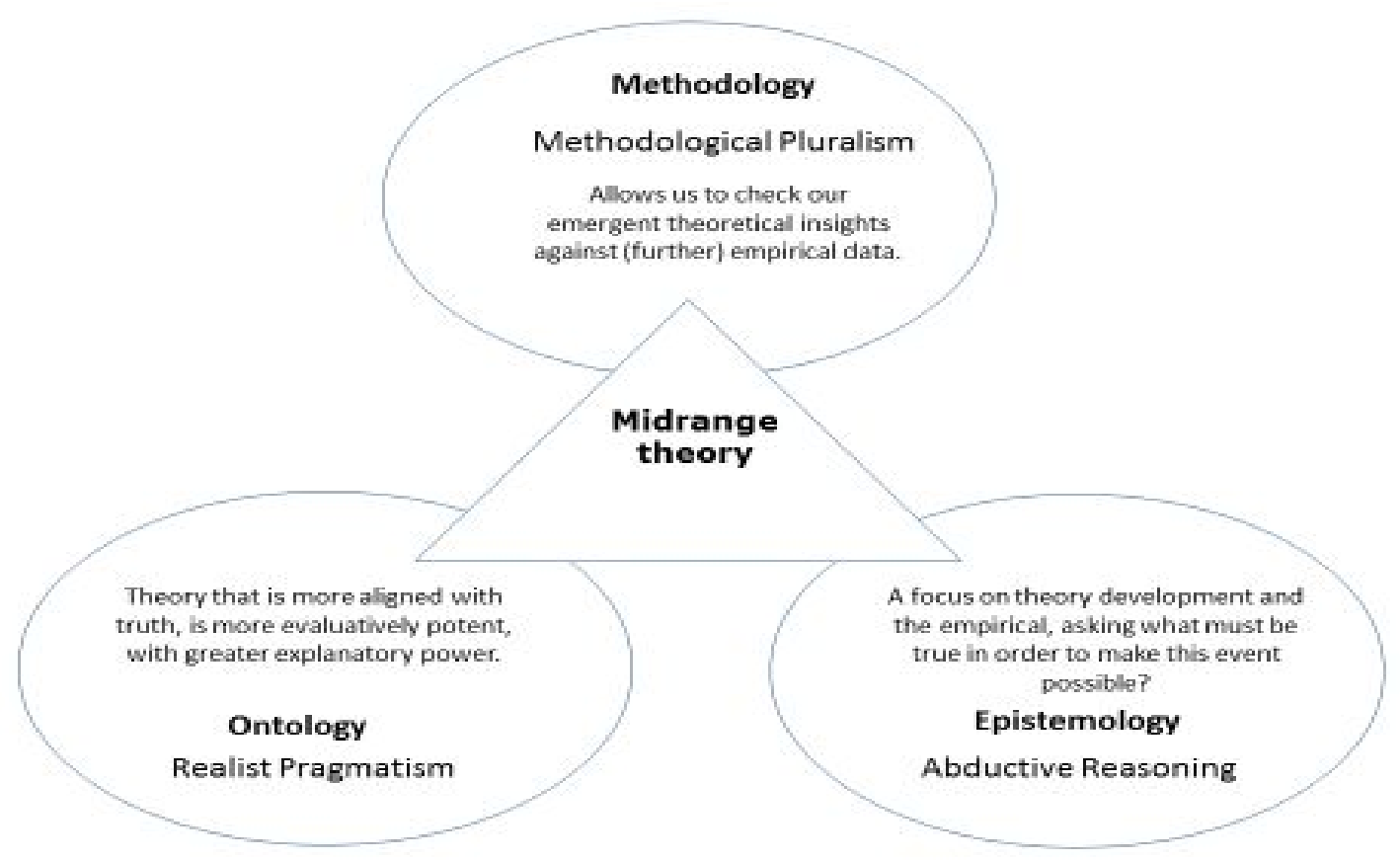


Figure 4: Sequence of Interfaces to Develop Midrange Theory for CE

1) Customer engagement: Conceptual domain, fundamental propositions, and implications for research (Brodie et al. 2011 a)

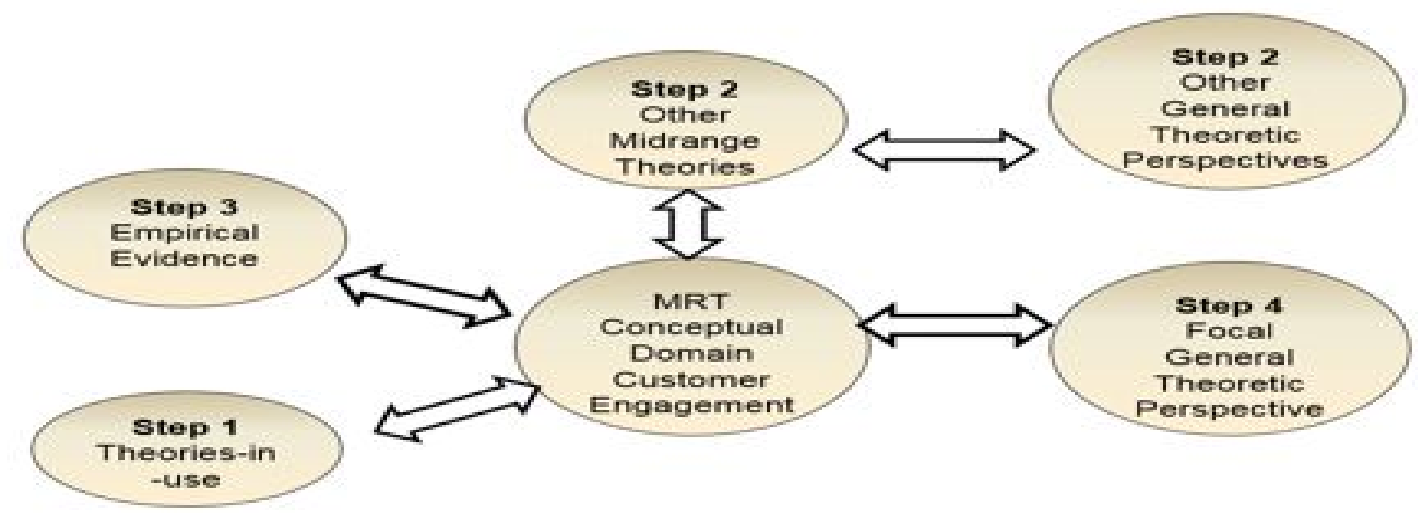

2) Consumer engagement in a virtual brand community: An exploratory analysis (Brodie et al. 2013)

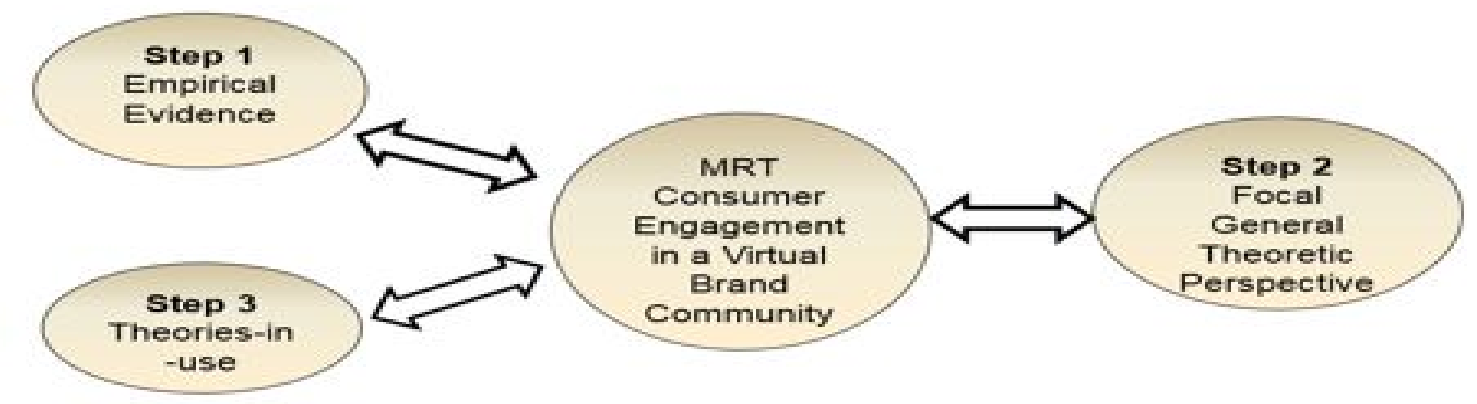

3) Consumer brand engagement in social media: Conceptualization, scale development, and validation (Hollebeek et al. 2014)

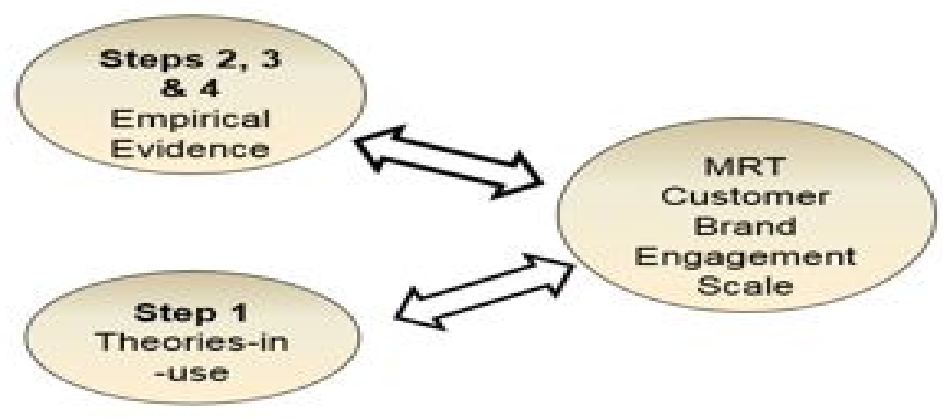

